\title{
Analyzing the International Refugee System for Solving the Problem of Climate Migration
}

\author{
Qingyu Zhang ${ }^{1 *}$, Shuhan $\mathrm{Gao}^{2}$, Yuzhou $\mathrm{Li}^{3}$, Yitong Zhang ${ }^{4}$ \\ ${ }^{1}$ School of Law, Ocean University of China, Qingdao, Shandong 266100, China \\ ${ }^{2}$ School of Law, University of International Relations, Beijing 100091, China \\ ${ }^{3}$ The Experimental High School Attached to Beijing Normal University, Beijing 100032, China \\ ${ }^{4}$ Guangzhou Foreign Language School, Guangzhou, Guangdong 511455, China \\ *Corresponding author. Email: zhangqingyu2000@outlook.com
}

\begin{abstract}
Climate migration, or climate-induced migration and displacement, is an emerging concept to describe migration caused by climate-related impacts and events, such as the long-term rising of sea level and the instant extreme weather disasters. Although the academic circles and the international community have observed that climate change may contribute to human displacements, meanwhile showing great concern for the issue, there is still not a globally recognized term in international law to define these migrants officially, or any international legal instruments to govern the rising displacements due to climate change. In an attempt to solve these problems in international law, this research paper will begin by discussing the situation of climate migration. Then, it will analyze several issues in the existing refugee-related international laws. Based on gaps figured out in the current international refugee system, the research paper finally proposes two possible methods for the international community to govern the urgent climate migration situation effectively. To be more specific, the current international refugee system should define climate migrant as climate refugees to protect and fill the legal gaps in related concepts and principles.
\end{abstract}

Keywords: climate migration, Refugee Convention, legal gaps, climate refugee

\section{Introduction}

The latest data, 'Displaced on the frontlines of the climate emergency', released on 22, April 2020[1], warns that the current situation of climate migrants is not optimistic. The number of new displacements caused by weather-related disasters has experienced a significant growth in the past ten years, from 15 million in 2009 to 21.5 million in 2019 , which is more than twice as many as displacements caused by conflicts. As for the future situation, Myers Norman predicates that the number of migrants related to climate change will amount to 200 million by 2050.[2] Among several individual cases, few climate migrants were recognized as refugees and admitted by another country, which indicates a lack of standard protection that can be delivered to those migrants who suffered from negative climate-related impacts. Current researches seek for a universal definition that can be given to climate migrants, as well as practical methods to tackle climate migrations, such as a new binding multilateral convention as Refugee Convention. However, these researches failed to reach a consensus. Thus, in order to give a uniform definition and standard of protection which can urge the global community to offer protection to migrants most in the need of assistance, this research proposes two solutions, trying to define climate migrants as "climate refugees" to protect them and modify the current Refugee Convention to cover the climate migrants.

This research now begins with environmental migrants. Environmental migrants are defined as "persons or groups of persons who, predominantly for reasons of sudden or progressive changes in the environment that adversely affect their lives or living conditions, are obliged to leave their habitual homes, or choose to do so, either temporarily or permanently, and who move within their country or abroad." [3] Under this broad term is several sub-branches. Environmental migration can be divided into domestic and international types, as suggested by the above definition. It can also be classified according to causes, and this leads to the research's primary focus: issues concerning 
international climate migrations.

\section{Climate migration}

\subsection{Causes of climate migration}

Previous researches have shown that most climate migrations were caused by extremely urgent climate disasters: Hurricane Eta in early November 2020, which has been considered as one of the most harmful climate catastrophes in Central America in the past twenty years, destroyed at least 6,900 homes in Nicaragua and 450 homes in Honduras. In the Dry Corridor (a region comprised of El Salvador, Guatemala, Honduras, and Nicaragua), 2.2 million people have been influenced by Torrential rain and flooding, with a drought that lasted for several months. Extreme weather accounts for 30 per cent of migrants.[4]

On the one hand, it is apparent that slow-onset climate conditions are constantly contributing to the massive climate change migration: global warming leads to a slow yet steady increase in both the strength of tropical hurricanes and the sea levels. As a result, it is predicted that $17 \%$ of Bangladesh will be submerged by the rising sea by 2050, and 20 million people living there will lose their homes permanently. [5] On the other hand, the severe drought and desertification is now sharply reducing food production in rural Sahel regions and northeast Brazil, eventually displacing countless residents from these areas annually for temporary survival.[6]

It can be concluded that the data and instances have clearly shown that climate degradation, especially global warming, can generate forced migration flows, and the next centuries will witness this situation become even worse.

\subsection{Situation of climate migration}

\subsubsection{The difficulty for the migrants to acquire the permanent residency}

It's hard to give those climate migrants permanent residency permission since host countries may face the threat of an increase in population.

Courts of high judicial authority from New Zealand Immigration and Protection Tribunal (IPT) have declared that "persons fleeing natural disaster" cannot obtain Convention-based protection.[7] New Zealand adopts the "Pacific Access Category" (PAC) program to help Tuvalu, Kiribati, and Tonga with annual immigration quotas to help those countries that suffer from the negative impact of climate change, but this does not apply to other types of immigration people. This is actually a useful attempt by the New Zealand government to deal with climate migration. However, the requirement for a more effective proposal is still urgent because of the limited quotas.[8]

\subsubsection{Case for the citizen of Kiribati and New Zealand}

In 2014, two citizens of Kiribati and Tuvalu who had lived in New Zealand for many years applied for climate refugee status in case of the negative effects of rising sea levels and land loss due to climate change, and hoped that the New Zealand government will recognize their "climate refugee status" so that they can continue to reside in New Zealand legally after their visas expire. The citizen of Kiribati was the first person in the world to apply for "climate refugee" status. However, the application ended in failure. The citizen of Tuvalu applied for the same reason and finally obtained permanent residency in New Zealand.[9] The judge from the New Zealand Immigration and Protection Tribunal considered that the appellant from Kiribati had not been subjected to any dispute in the past. Besides, there was no evidence showing that he faced a real chance of suffering serious physical harm from violence linked to Humanitarian Law Project disputes in the future.[10] In the case of the Tuvaluan citizen, the court held that their relatives have obtained permanent residency in New Zealand, which enabled them to establish a solid connection with the place where they settled. They could obtain New Zealand residency for humanitarian reasons. However, it is believed that the lives of Tuvaluan citizens after returning to Tuvalu may not be affected by the climate change, therefore, they cannot be recognized as refugees.

There is no unified standard in international law, so different countries may hold different attitudes towards climate migrations. Therefore, domestic laws vary from country to country. The judgment from the case shows that climate change is not enough to determine residence rights or the basis for determining climate refugee status. To improve the situation, it requires international law to set a standard and offer protection.

\section{Existing international law on refugees}

\subsection{Who are covered by existing law?}

The 1951 Refugee Convention defines refugee as "a person who has lost the protection of their state of origin or nationality. It is essentially the loss, or failure, of state protection which makes international protection necessary for refugees." "A well-founded fear of persecution based on reasons specified above, and being outside the country of origin, nationality, or habitual residence evidenced by unwillingness to return to such a country, are all significant elements in the definition of a refugee.", stated the Convention. However, as "the convention was adopted in the immediate post-World 
War II period, when the refugee problems confronting the international community were mainly those of refugees of European origin", it did not discuss climate migrants. Some scholars argue the irrationality of including climate migrants into the current refugee system, warning not to draw a causative line between climate change and refugees. Scholar Lonergan even argues in his report that the "environmental refugee" contradicts political refugee recognized by the 1951 and 1967 Convention because they did not experience the types of persecution specified in the document. These "environmental refugees" should instead be referred to as environmentally displaced people.[11]

\subsection{Gaps in international law in governing the climate migration}

Some states may offer certain assistances to victims of disasters that migrate to their territory. However, the international law still contains multiple gaps when it comes to climate migrants' issues, failing to bind international recognition or protection for climate migrants.

\subsubsection{Voluntary standards}

2005 Hyogo Framework for Action, and other human rights-related principles for disaster victims, are kinds of soft laws which have no legally binding effects. For instance, while the 2005 Hyogo Framework for Action focuses on the construction of disaster preparedness system in many countries, most countries still fail to integrate disaster risk considerations and climate migration problems into further development plan.[12] Similarly, with the United Nations High Commissioner for Refugees owning the mandate to climate migration cases, it is not host states' legal obligation to issue temporary or permanent refugee status for those climate migrants. The current Temporary Protected Status is considerably narrow, which is not applicable for international cases related to climate migration.

\subsubsection{Long term slow change}

Although long term drought events may not be as significant as sudden weather disasters which grab the public attention instantly, many victims of slow-onset drought disasters also seek protection and employment opportunity outside the drought-affected area, just like those suffering from rapid-onset disasters. Yet for most governments, assistance offered to climate migrants are confined to several living necessities, like shelter and food, instead of employment opportunities. Lack of income deprives the refugees' ability to live independently in new safe areas and, eventually, their basic human dignity. For example, drought and resource conflicts contribute to the mass migration to Kenya.
However, these migrants tend not to be treated as "refugees" or to enter the refugee camps because the Kenyan law does not give permission for them to work and travel at will.[13]

\subsubsection{International immigrants are not well treated as internally moved refugees}

Under the 1951 Convention relating to the Status of Refugees persons fleeing environmental harm are not identified as international refugees.[14] Thus, regarding migration management regimes in most countries, massive climate migrants crossing the international borderlines are not well treated as internally moved migrants. If they migrate across the international border but are not admitted as refugees, they may be criminally charged, discriminated, or be repatriated to an unknown circumstance.

\subsection{Why should climate migrants be protected under refugee standards?}

Because of the slow nature of climate change (temperature has only risen a mere 1.5 degrees Celsius above pre-industrial level, but has significantly shaped the earth's environment in the past few centuries [15]), related problems including climate migrants has rarely attracted enough attention in the international community. Fortunately, this situation is changing. Over the past three decades, research on migration and the environment has in general increased.[16] The International Bank's Groundswell report in 2018 shows that by 2050 , climate change will force 216 million people to migrate.[17] This data demonstrates the severity of climate change as well as the prominent problems of climate migrants. As victims of environmental disasters, these people deserve to be protected by the global community, under equitable standards with other refugees identified by the 1951 and 1967 Convention. They differ from migrants who are in pursuit of better living conditions. These climate migrants resemble currently defined refugees in the way that they are forced to leave their homeland. The former is due to environmental reasons and the latter political ones. In essence, they are in the same situation.

\section{Solutions}

\subsection{Defining climate migrants as climate refugees in international law}

\subsubsection{Controversies in defining climate migrants as climate refugees}

The first solution to govern climate-induced migration is to define some of the migrants as climate refugees because existing refugee laws do not cover 
migrants who suffer from disasters caused by climate change, and a clear definition will make the international community better understand this problem. However, some proposals to recognize climate migrants as 'climate refugees' in an international legal instrument raise extensive debates, which may mainly come from the following three aspects:

Firstly, there are conceptual differences between traditional refugees and the climate migrants. The existing definition of refugee, given by the 1951 Refugee Convention, is a person who may confront with some certain persecutions in their home country. Persecution generally refers to unfair treatment based upon one's race, religion, nationality, or some political opinions. However, climate change, which does not threaten human life imminently and discriminately based on certain characteristics, is hard to be regarded as a kind of 'persecution'. Thus, there is a debate about whether it is justifiable to define climate migrants as refugees under protection.

Secondly, migration is caused by a combination of factors, with climate change among them. However, it is difficult to distinguish migration caused by climate change from such factors as political, economic, or social factors, etc. [18] Therefore, the lack of direct causation between climate change and migration makes defining climate-induced migrants as climate refugees a problem. Mostafa Mahmud Naser also shows his concern that the multi-causality of climate migration may become an excuse for policymakers to deny the refugee right of climate migrants.[19]

Thirdly, responses to climate change are varied. Naser argues that migration can sometimes be considered as an active strategy to deal with climate change instead of a passive remedy in the aftermath.[20] Some people may choose migration proactively as a precaution to deteriorating domestic living conditions due to climate change. However, some people are migrants who have no choice but are forced to leave homelands where the worst circumstance already exists. Some migrants only move internally, while others may flee to other countries. These diverse responses from different people to climate change lead to the inaccuracy of generally defining all climate migrants as refugees in international law.

\subsubsection{Defining climate migrants as climate refugee in international law}

Controversies do exist in recognizing climate migrants as refugees. However, considering the urgent situation to govern climate migration and displacement, it is of great significance to give a universally acknowledged term to them at the international law level, which can guide the international community to provide effective and accurate protection to migrants who are most in need of help.

Concerning the controversies mentioned above, the following four aspects should be clarified with the aim of defining climate migrants as climate refugee at the level of international law.

\section{(1)A new classification of protection for climate} refugee

In regard to the conceptual differences between traditional refugees and climate migrants, a domestic legislation, the Swedish Aliens Act, will be a valuable reference. It creates a separate category of protection to cover aliens who cannot return to their own countries due to 'environmental disasters'. Hopefully, it may also be practicable to set a new classification for climate migrants and distinguish them from refugees who are persecuted for political reasons in the existing Refugee Convention.

\section{(2)Involuntariness}

Involuntariness is not only a criterion to distinguish climate refugees from general climate-induced migrants, but also a connection to link the concept of climate refugee with traditional political refugee. Climate-induced migration can be either voluntary or involuntary. However, climate refugee, a much more rigorous concept, should only refer to those who are facing the existing worst situations and have no choice but to flee, seeking elsewhere for protection. In the meantime, involuntariness is also a characteristic of political refugees who are in fear of certain political persecutions and unable to get protection from their country of their nationality, so they are reluctant to return. Climate migrants, with the similar involuntary nature, will be recognized as climate refugees. For example, migrants from Tuvalu may be considered as climate refugees who are confronted with the worst situation in their domestic country because Tuvalu government has declared its failure to govern the rising of sea level due to climate change. This means that residents in Tuvalu may gain no protection from their national government when they are displaced due to climate-related disasters and become homeless one day, just as political refugees.

\section{(3)Cross-international border}

The definition of climate refugees should be issued to cross-international border involuntary migration due to climate change only. To define climate refugees on the level of international law, it is more feasible to only cover the cross-international border migration. The situation of internal migrations can greatly vary within different states, therefore giving an identical definition to internal migration may not be operative for countries to apply flexible solutions based upon their own domestic situation. Therefore, a definition that covers the cross-border migration only will be more acceptable 
for the international community, which may guide countries to work collectively in dealing this transnational challenge.

\section{(4)Types of influences}

A weakness observed in Sweden domestic legislation is that it did not give a clear explanation to 'environmental disasters' when defining environmental refugees. International law may improve this weakness. Given that there still lacks a direct causation between climate change and migration, the definition for climate refugees in international law is supposed to identify several significant climate-related influences which qualify migrants suffering from those as climate refugees. To be more specific, these influences should include the rising of sea level, the extreme weather conditions, and disasters related to extreme weather conditions, such as drought and flood. These narrow specifications will also distinguish climate refugee from the general concept of environmental refugee who may migrate due to non-climate change factors.

In conclusion, climate refugee should be defined by four main aspects. An explicit definition for climate refugee in international law will also guide the international community and countries to solve this global problem.

\subsection{Supplements to current legal system}

To handle the urgent situation, the second necessary solution is to fill up the legal gaps. Based on the current Refugee Convention, defining the climate migrations as the climate refugees with the corresponding limitations and giving them legal protection are the best solutions. Firstly, expanding the concept of traditional refugee to the climate refugee can be effective to the protection of those climate migrants. Because compared to traditional refugees, those climate migrants may suffer more actual damages from climate change. Secondly, based on the principle of Common and Separate Responsibilities, the international community should assume corresponding responsibilities according to its own capabilities and establish a protection mechanism for existing and potential climate refugees. But determining the capacity for a country to receive refugees requires an international evaluation mechanism. Thirdly, applying the principle of Non-refoulment in Refugee Convention requires member states to examine the actual or latent situation of the applicant in responding to climate change and protect the right to live from infringement. If the appellant can prove that the danger that climate change brings to him or her is urgent and serious, the receiving country should provide temporary help. Those climate migrants, once recognized as climate refugees, should be provided with the fund support guarantee system, governance mechanism guarantee system, and international litigation guarantee system.[21]
From the perspective of human rights law, the damaging effects of climate change on human health and well-being have created obstacles to the enjoyment and realization of basic human rights. In 2008, the United Nations Human Rights Council adopted a resolution, which stated that "climate change poses a direct and far-reaching threat to people and communities around the world" [22]. According to International Covenant on economic, social and cultural rights and International Covenant on Civil and Political Rights, if people's basic right might be infringed, there should be solutions to protect their human rights. Thus, out of humanitarianism, the international community should also help climate migrants whose homes have been devastated by natural factors.

\subsection{Other solutions}

Other solutions to tackle the definition problem of climate migrants may include:

(1) Signing a new treaty on environmental migration defining these climate migrants.

(2) Using domestic law as the only reference to these migrants.

Regarding the solution of signing a new treaty, a newly-signed treaty must include climate change, which was neglected in the 1951 and 1967 Convention, as a new reason for persecution. Different kinds of protections for environmental migrants should also be proposed in the new treaty, addressing the difference between them and political refugees. Nevertheless, the process of signing a new treaty can be complicated and tedious and is unlikely to yield a satisfying result in light of different states' interests. In response to the option of using domestic law, they can be used as references in the new refugee Convention, but they may also lead chaos in global society without a unified standard. Climate change is a global problem, and no single state alone is able to grapple with it; collective effort is needed in addressing the problem of international climate migrants.

Modifying the existing refugee Convention remains the optimal solution. The new Convention must firstly use data to show the suitability of defining "climate changes" as a "persecution". Due to the slow nature of climate changes, this new Refugee Convention that centers on climate migrants should then take precautions by controlling the extent of climate change. It can, as the last means, set quotas according to countries' capacities to host future refugees.

\section{Conclusion}

The research presents that the current and future situation of climate migration will be worse and more urgent. The existing international refugee system, 
however, fails to solve this transnational problem. In order to raise extensive global attention and deal with the ineffectiveness of the existing international refugee system, the research proposes two solutions. The first is to define climate migrants as climate refugees officially in order to better protect them, and the second is to make supplements to the current refugee system. Considering that international law is an open system with changes in circumstances, and climate change is also a dynamic concept, it is practicable to broaden the existing refugee system to cover climate migrants. In addition, defining climate migrants and making several supplements in the existing refugee laws, compared with signing a new treaty for the protection and support of climate migrants which may be a long way to achieve countries' consensus and ratification, can be much preferable with a relatively lower cost.

In sum, this research contributes to the identification of several legal gaps in the international law with regard to displacements caused by climate change, and proposes two innovative methods to fill the gaps, in the expectation that the global community will take strong multilateral actions to handle the issue effectively.

\section{References}

[1]. The UN Refugee Agency. (2020) Displaced on the frontlines of the climate emergency. https://storymaps.arcgis.com/stories/065d18218b65 4c798ae9f360a626d903.

[2]. Myers, N. (2005) Environmental Refugees: An Emergent Security Issue. In: 13th Economic Forum. Prague. pp. 23-27

[3]. Melde, S. (2014) Migration, Environment and Climate Change: Evidence for Policy (MECLEP) Glossary. International Organization for Migration (IOM), The Geneva.

[4]. World Food Program USA. (2021) The Dry Corridor in Central America. https://www.wfpusa.org/emergencies/drycorridor/.

[5]. Tetsuji Ida. (2021) Climate Refugees - the World's Forgotten

Victims. https://www.weforum.org/agenda/2021/06/climaterefugees-the-world-s-forgotten-victims/.

[6]. Piguet, E. (2008) Climate change and forced migration. New Issues in Refugee Research Research Paper 153

[7]. Applicant A v Minister of Immigration and Multiethnic Affairs [1998] INLR 1, p19

[8]. Shi, X., Liu, H. (2016) The Difficulties and Countermeasures in the Protection of Climate Immigrants by International Law. Nankai Journal
(Philosophy and Social Sciences Edition) 06(2016):68-77.

[9]. Jacovella, G. (2015) International Law and the (De) Politicisation of Climate Change and Migration: Lessons from the Pacific. SOAS L.J., No. 2: 87-91.

[10].New Zealand Legal Information Institute. (2013) AF (Kiribati) [2013] NZIPT 800413. http://www.nzlii.org/nz/cases/NZIPT/2013/800413. html.

[11].Lonergan, S. (1998) The role of environmental degradation in population displacement. Environmental Change \& Security Project Report, 4(4): 5.

[12].United Nations Office for Disaster Risk Reduction. (2005) The Hyogo Framework for Action (HFA). https://www.preventionweb.net/sendai-framework/ Hyogo-Framework-for-Action

[13].Michelle, L. (2010) Climate change and migration: key issues for legal protection of migrants and displaced persons. https://seors.unfccc.int/applications/seors/attachme nts/get_attachment?code=NL2KZ9POSH0E2SR1H SP6B58BH1KCUJE3.

[14].Michelle, L. (2010) Climate change and migration: key issues for legal protection of migrants and displaced

persons. https://seors.unfecc.int/applications/seors/attachme nts/get_attachment?code=NL2KZ9POSH0E2SR1H SP6B58BH1KCUJE3.

[15].The Intergovernmental Panel on Climate Change. (2018) Special Report, Global Warming of $1.5^{\circ} \mathrm{C}$. https://www.ipcc.ch/sr15/.

[16].IOM's GMDAC. (2018) Number of Publication and Case Studies on Migration, Environment and Climate Change. https://www.migrationdataportal.org/.

[17].The World Bank. (2018) Climate Change Could Force 216 Million People to Migrate Within Their Own Countries by 2050. https://www.worldbank.org/.

[18].Wyman, K. M. (2013) Responses to climate migration. The Harvard environmental law review: HELR, 37(1): 167-216.

[19].Naser, M. M. (2012) Climate Change, Environmental Degradation, and Migration: A Complex Nexus.William and Mary Environmental Law and Policy Review, 36: 713-768

[20].Naser, M. M. (2012) Climate Change, Environmental Degradation, and Migration: A Complex Nexus.William and Mary Environmental 
Law and Policy Review, 36: 713-768

[21].Yu, C. (2016) Study On The Basic Questions Of International Climate Refugees Legislation. China University of Political Science and Law, MA thesis.

[22].Human Rights Council (2008) Resolution 7/23.

Human rights and climate change. https://www.right-docs.org/doc/a-hrc-res-7-23/. 